\title{
Hepatoprotective Activity of Spices
}

\author{
Sri Neeraja .P \\ Intern, Saveetha Dental College and Hospitals, Chennai, India
}

\begin{abstract}
In history, spices have often been more valuable than gold or precious stones, and the trade of spices has been an extraordinarily influential factor. Many researchers have attempted to explain why spices are pleasant to taste. This work intends to aid researchers in the study of natural products useful in the treatment of liver diseases.The present work constitutes a review of the spices of natural origin with hepatoprotective activity.
\end{abstract}

Keywords: Hepatoprotective, cardamom, cloves, garlic, ginger, nutmeg, turmeric

\section{Introduction}

This extensive flora has been greatly utilised as a source of many drugs in the Indian traditional system of medicine. In India, the earliest mention of the use of medicinal plants is to be found in Rigveda which was written between 4500-1600 BC. Spices are the very heart of Indian cooking. They have been used since ancient times. They were mentioned in the ancient Hindu scriptures called the Vedas, ancient Egyptian papyruses and the Old Testament. Although it was not until the Roman conquests that western counties discovered their culinary possibilities, spices have always been believed to have healing and magical qualities. They have been used to cast spells, as incense in religious rites, to embalm corpses, to add aroma to perfumes and as aphrodisiacs. The word spice comes from Latin species, meaning a commodity of value and distinction.

The liver is one the prime organ concerned with several states of metabolic and physiologic homeostasis of the human beings. About 20,000 deaths found every year due to liver disorders.Liver diseases are a major worldwide health problem, with high endemicity in developing countries. They are mainly caused by chemicals and some drugs when taken in very high doses. Despite advances in modern medicine, there is no effective drug available that stimulates liver function, offer protection to the liver from damage or help to regenerate hepatic cells. There is urgent need, therefore, for effective drugs to replace/supplement those in current use. The plant kingdom is undoubtedly valuable as a source of new medicinal agents.

\section{Cardamom}

It is the seed of a tropical fruit in the ginger family. Fruits and seeds leave pleasant aroma with sweet, pungent taste behind when chewed It is used in Ayurvedic medicine to remove fat and as a cure for urinary and skin complaints. Egyptians chewed cardamoms to whiten their teeth and simultaneously sweeten their breath. The seeds are aromatic, sweet cooling, carminative (cures flatulence), digestive, stimulant and tonic. Cardamom finds usage in indigestion, anorexia, burning sensation, debility, asthma. Amomumsubulatumshowed anti-ulcerogenic effects, hepatoprotective activity and as fungitoxitant. It also has antispasmodic activity. [1] [3]

Cloves- small, dried, reddish-brown flower bud of the tropical evergreen tree of the myrtle family. They have strong, sweet aroma and hot, pungent taste, They have been used in India for thousands of years, not only in cooking, but to sweeten the breath and to relieve the pain of toothache. They contain a mild anesthetic.It prevents vomiting during pregnancy,helps in digestion and has inhibitory effect on histamine production. [2] [3] [4]

Nutmeg- is the seed of the evergreen tree Nutmeg has more robust flavor. They have nutty, warm and slightly sweet flavor. Nutmeg is used to add sweet and savory flavor to dishes such as pies, custards, puddings, cakes, soufflés, vegetables, egg dishes, lamb, and fish, and beverages. Nutmeg prevents theaccumulation of cholesterol, phospholipids andtriglycerides in liver, heart and aorta and dissolvedatheromatous plaques of aorta. [5] [6]

Garlic - closely related to the onion. It has a powerful pungent or hot flavor when raw, which mellows when it is cooked. It has very strong odor. Garlic helps to purify the blood and lower blood pressure. It is considered as a cure for heart ailments.The high percentage of cysteine in garlicprotein and the reactive disulphide group in the oil are beneficial for liver. [6] [7] [8] [9]

Ginger - the fresh root gingeris a knobly rhizome with a sweet aroma and hot, pungent taste. Ginger is also commonly regarded as an aphrodisiac.Ginger in diet increases the rate of protein synthesis leading to the higher concentration of albumin andprotein in the liver.gingerbased diet maintains theintegrity of the liver and protects it against damage caused by carbon-tetrachloride inducedhepatotoxocity. [10] [11] [12]

Turmeric- comes from the root of Curcuma longa, a leafy plant related to ginger. It has a bright yellow colour and a pungent, warm, earthy aroma and taste. Turmeric is prepared by grinding of dried rhizomes mainly from Curcuma longa L. of the Zingiberaceae family it has been used by the food industry as additive, flavouring, preservative, and colouring agent. Commercially available turmeric may contain essential oils, polyphenols, protein, fat, minerals, carbohydrates, and moisture. The aromatic properties of turmeric are thought to be attributable to its volatile essential oils.

It is mildly antiseptic. It is used in curries, fish dishes and with beans because of its digestive properties. Research show that turmeric inhibits blood clotting, reduces liver

\section{Volume 6 Issue 7, July 2017




\section{International Journal of Science and Research (IJSR) \\ ISSN (Online): 2319-7064 \\ Index Copernicus Value (2015): 78.96 | Impact Factor (2015): 6.391}

toxins, and helps the liver metabolize fats and so aids weight loss

Curcumin downregulates various pro-inflammatory cytokine expressions such as tumour necrosis factor (TNF- $\alpha$ ), interleukins (IL-1, IL-2, IL-6, IL-8, IL-12) and chemokines, most likely through inactivation of the nuclear transcription factor, nuclear factor (NF)- $\kappa \mathrm{B}$. Curcumin is known to decrease the inflammation associated with experimental colitis, including a substantial reduction of the rise in myleoperoxidase (MPO) activity, an established marker for inflammatory cells (mainly polymorphonuclear leukocytes) and TNF- $\alpha$. And it is able to reduce colonic nitrite levels and downregulate cyclooxygenase (COX)-2, inducible nitric oxide synthase ( $i$ NOS) expression and p38 mitogen activated protein kinase (MAPK) activation.

Curcumin, the most common antioxidant constituent of Curcuma longa rhizome extract, was reported to enhance apoptosis of damaged hepatocytes which might be the protective mechanism wherebycurcumin down-regulated inflammatory effects and fibrogenesis of the liver.

The hepatoprotective effects of turmeric and curcumin might be due to direct antioxidant and freeradical scavenging mechanisms, as well as the ability to indirectly augment glutathione levels, thereby aiding in hepatic detoxification. The volatile oils and curcumin of Curcuma longa exhibit potent anti-inflammatory effects.

As a traditional medicine, turmeric has also been extensively used for centuries to treat a diversity of disorders including rheumatism, body aches, skin diseases, wounds, intestinal worms, diarrhoea, intermittent fevers, hepatic disorders, biliousness, urinary discharges, dyspepsia, inflammation, constipation, leukoderma, amenorrhoea and colic inflammation.

Combined treatment of curcumin and gingermaximize the protection of liver from injury and fibrogenesis due to $\mathrm{CCl} 4$ intoxication.curcumin and ginger returned collagen fiber distribution to almost normal pattern. [12-17]

\section{Results and Discussion}

Hepatic cells participate in a variety of metabolic activities and contain a host of enzymes. AST and ALT are reliable markers of liver function which are found in higher concentrations in the cytoplasm and an altered form of AST also exists in the hepatocyte mitochondria. Although both transaminase enzymes are widely distributed in other tissues of the body, the activities of ALT outside the liver are low and therefore this enzyme is considered more specific for hepatocellular damage. During liver injury, transport function of the hepatocytes is disturbed which leads to leakage of plasma membrane, thereby causing an increased enzyme level in serum and soluble enzymes like AST will also be similarly released. Estimation of these enzymes in serum is a useful quantitative marker for the extent and different types of hepatocellular damage. The present study elevated activities of AST and ALT in serum were observed in paracetamol administered rats which indicates increased permeability, damage and/or necrosis of hepatocytes.
Natural antioxidants that are present in herbs andspices are responsible for inhibiting or preventing thedeleterious consequences of oxidative stress. Spices andherbs contain free radical scavengers like polyphenols,flavonoids and phenolic compounds.

The phytochemical tests indicated the presence of alkaloids, glycosides, tannins, and flavonoids in the crude methanolic extract. Several of such compounds are known to possess potent antioxidant activity.

\section{References}

[1] KhareDivya Prakash, Kumar Brajesh ,HussainArshad, VermaShikhar, Mishra Mala. Evaluation of antioxidant activity of large cardamom (leaves of Amomumsubulatum). Int. J. Drug Dev. \& Res., JanMarch 2012, 4 (1): 175-179.

[2] MuthiahMaridass.Hepatoprotective Activity Of Barks Extract Of Six Cinnamomum Species On Carbon Tetrachloride-Induced In Albino Rats. Folia MedicaIndonesiana Vol. 45 No. 3 July - September 2009: 204-207.

[3] Ola El-Segaey Et Al.Experimental Study Of Antioxidant And Hepatoprotective Effects Of Clove And Cardomom In Ethanol Induced Hepatotoxicity.Tanta Medical Sciences Journal Vol.(2), No.(1),January 2007:Pp 27-36 ISSN: 1687-5788.

[4] Heinerman, J. The complete book of spices, their medical, nutritional and cooking uses. 1983, New Canaan, CT: Keats publishing Inc.

[5] Essam F. Al-Jumaily1, Maytham H. A. Al-Amiry1, Jaleel I. Assad Et Al.Hepatotoxic Activity Of Essential Oil From Nutmeg (MyristicaFragrans) Against Tetrachloride-Induced Hepatic Damage In Mice. ISSN: 2278-3008 Volume 2, Issue 6 (Sep.-Oct. 2012), PP 0108 .

[6] Dahanukar SA, Kulkarni RA, Rege NN. Pharmacology of medicinal plants and natural products. Indian $\mathrm{J}$ Pharmacol 2000; 32 : S81-118.

[7] Nooman A. Khalaf, Ashok K. Shakya, Atif Al-Othman, Zaha El-Agbar, Husni Farah et al. Antioxidant Activity of Some Common Plants. Turk J Biol 32 (2008) 51-55.

[8] Mathew BC, Augusti KT. Biochemical effects of garlic proteindiet and garlic oil on glycosaminoglycan metabolismin cholesterol fed rats. Indian J ExpBiol 1996;34:346-50.

[9] Mohamed NaguiT.Attia, MagdyA.Ali Et Al. Hepatoprotective Activity Of Allicin Against Carbon Tertrachloride Induced Hepatic Injury InRats.journal of biological sciences 6 (3): 457-468, 2006 ISSN 1727 3048.

[10] Kazeem, M.I, Bankole, H.A, Fatai, A.A et al.Protective effect of ginger in normal and carbon-tetrachloride induced hepatotoxic rats. Annals of Biological Research, 2011, 2 (1):1-8.

[11] Nemat, A., E. Yassin, M. Siham, A. Nermine, H. Wael, M. Hebaet al., 2010. Study of the hepatoprotectiveeffect of ginger aqueous infusion in rats. J chem..pharma. Res., (2): 476-488.

[12] Magda K. Ezz, Germine M. Hamdy ,Rasha M. Abd El Atti et al.The Synergistic Hepatoprotective Effect of Curcumin aAnd Ginger Against Carbon Tetrachloride 


\section{International Journal of Science and Research (IJSR) \\ ISSN (Online): 2319-7064}

Index Copernicus Value (2015): 78.96 | Impact Factor (2015): 6.391

Induced- Liver Fibrosis in Rats. Aust. J. Basic \& Appl. Sci., 5(9): 1962-1971, 2011.

[13] Krup V, Prakash LH, Harini A (2013) Pharmacological Activities of Turmeric (Curcuma longa linn): A Review. J HomeopAyurv Med 2: 133.

[14] Salama SM, Alrashdi AS, Ismail S, AlkiyumiSS, Abdulla MA, et al. (2013)Hepatoprotective effect of ethanolic extract of Curcuma longa onthioacetamideinduced liver cirrhosis in rats. BMC Complementary and Alternative Medicine13: 56.

[15] Purusotam Basnet, Natasa Skalko-Basnet et al. Curcumin: An Anti-Inflammatory Molecule from a Curry Spice on the Path to Cancer Treatment. Molecules 2011, 16, 4567-4598.

[16]M. Akram1, Shahab-Uddin, Afzal Ahmed, Khan Usmanghani,AbdulHannan, E. Mohiuddin, M. Asif et al.Curcuma Longa And Curcumin: A Review Article. ROM. J. BIOL. - PLANT BIOL., VOLUME 55, No. 2, P. 65-70, BUCHAREST, 2010.

[17] Rafael, B., A. Michal, W. Sigal, G. Ilana, S. Haim, A. Hussein et al., 2007. Prevention of liver cirrhosis inrats by curcumin. Liver Int., (27): 373-383. 